\title{
Expression of Neurofilament Subunits in Neurons of the Central and Peripheral Nervous System: An Immunohistochemical Study with Monoclonal Antibodies
}

\author{
J. Q. Trojanowski, N. Walkenstein, and V. M.-Y. Lee \\ The Division of Neuropathology, Department of Pathology and Laboratory Medicine, \\ The University of Pennsylvania School of Medicine, Philadelphia, Pennsylvania 19104
}

The extent to which all neurofilament (NF) subunits (NF68, NF150, NF200) are expressed by different populations of mature CNS and PNS neurons is controversial. We addressed this issue in immunohistochemical studies of mature bovine tissues using monoclonal antibodies specific for each bovine NF subunit.

All three NF subunits were detected in the perikarya and neurites of both CNS and PNS neurons; they were seen in nearly all PNS neuronal perikarya, and in all identifiable CNS and PNS axons. Most, but not all, CNS neuronal perikarya contained each of these NF antigens. CNS neurons devoid of immunodetectable NF antigens were generally small. The presence of low levels of NF antigens in neurons with scant perikaryal cytoplasm may account for the apparent absence of NF immunoreactivity in some classes of neurons, although other explanations, such as microheterogeneity among NF proteins, could account for this finding.

NF antigens were also seen in some cells of the diffuse neuroendocrine system (adrenal chromaffin cells and cells of the pars distalis and pars intermedia), but not in other cell types.

We suggest that the expression of all three NF subunits is a common feature of CNS and PNS neurons and their processes, and of some cells of the diffuse neuroendocrine system. These findings have implications for hypotheses concerning the structure and function of the intermediate filaments of neurons, and for hypotheses concerning neurodegenerative diseases involving NF proteins.

The structure and function of intermediate filaments are incompletely understood. Neurofilaments (NFs) are composed of three subunits with apparent molecular weights of 200,000 (NF200), 150,000 (NF150) and 68,000 (NF68) Da (Liem et al., 1978; Schlaepfer and Freeman, 1978). They are separate gene products (Csoznek et al., 1980) and are immunochemically distinct (Lee et al., 1982b). Although NF200, NF150, and NF68 have been localized to 10 -nm-diameter filaments in neurons (Hirokawa et al., 1984; Schlaepfer et al., 1981; Sharp et al., 1982; Willard and Simon, 1981), some neurons or portions of some neurons appear to lack one or more NF subunits (Dahl,

Received Feb. 19, 1985; revised May 3, 1985; accepted June 14, 1985.

This work was supported in part by NIH Grants CA-36245 (J.Q.T.) and NS18616 (V.M.-Y.L.). J.Q.T. is the recipient of Teacher Investigator Development Award KO7 NS-00762. Appreciation is expressed to Drs. M. J. Carden and W W. Schlaepfer for helpful critical comments, and to Ms. M. Obrocka for invaluable help.

Correspondence should be addressed to Dr. Trojanowski at Division of Neuropathology, Department of Pathology and Laboratory of Medicine, University of Pennsylvania School of Medicine, Johnson Pavilion G2, Philadelphia, PA 19104.

Copyright (C) 1986 Society for Neuroscience $0270-6474 / 86 / 030650-11 \$ 02.00 / 0$
1983; Shaw et al., 1981). For example, Sharp et al. (1982) were able to distinguish two classes of neurons in PNS ganglia based on the presence or absence of NF proteins.

The absence of one or more NF subunits in some neurons would necessitate different hypotheses concerning the structure and function of NFs. Alternatively, microheterogeneity among NF proteins due to the phosphorylation state of these polypeptides, or as a consequence of unknown mechanisms, may account for the apparent variable expression of these proteins in neurons (Goldstein et al., 1983; Nixon et al., 1982; Sternberger and Sternberger, 1983). Other explanations, such as limitations in the methods used to identify NF subunits in situ, are also possible (Hickey et al., 1983).

Immunohistochemical studies of the in situ distribution of NF subunits have appeared (Dahl, 1983; Goldstein et al., 1983; Gown and Vogel, 1984; Hickey et al., 1983; Ostermann et al., 1983; Sharp et al., 1982; Shaw et al., 1981; Sternberger and Sternberger, 1983; Yen and Fields, 1981). However, only limited populations of CNS or PNS neurons were sampled, and cells of the diffuse neuroendocrine system, which share some properties of neurons (Marangos et al., 1982; Nolan et al., 1985), were incompletely studied. Further, antibodies specific for each of the three NF subunits rarely were used in such studies, many of which were conducted using indirect immunofluorescence rather than more sensitive immunoperoxidase methods (Hsu et al., 1981; Sternberger, 1979). Finally, marked immunochemical differences among NF polypeptides from different vertebrates were reported recently (Shaw and Weber, 1984; Shaw et al., 1984), and these differences were often not considered in earlier immunohistochemical studies of NF subunits. Any one of the factors mentioned above could account for the apparent absence of one or more NF subunits in different populations of CNS and PNS neurons.

In view of these considerations, we probed the distribution of each of the NF triplet proteins in a wide variety of bovine tissues using immunoperoxidase methods and monoclonal antibodies specific for bovine NF antigens.

\section{Materials and Methods}

\section{Monoclonal antibodies specific for NF triplet proteins}

Sixteen fusions with mouse myeloma cells (SP2/0-AG14) and splenocytes from Lewis rats immunized with bovine immunogens have yielded a library of over 200 monoclonal antibodies specific for NF subunits. A number of monoclonal antibodies from this library, together with the specifics of the fusions and antibody characterization studies, have been described (Lee et al., 1982b, 1984). The other anti-NF monoclonal antibodies havc bccn characterized in a similar manner. The specificities of these monoclonal antibodies for bovine NF proteins were determined as follows: (1) enzyme-linked immunosorbant assay using purified bovine NF proteins; (2) immunoblot studies on cytoskeletal ex- 
Table 1. Monoclonal antibodies to NF polypeptides and GF protein

\begin{tabular}{|c|c|c|}
\hline $\begin{array}{l}\text { Monoclonal } \\
\text { antibody }\end{array}$ & $\begin{array}{l}\text { Polypeptide } \\
\text { specificity }\end{array}$ & $\begin{array}{l}\text { Phosphorylation state } \\
\text { and subunit topography }\end{array}$ \\
\hline $\mathrm{SE} 3$ (SE1.2B12) & NF68 & Noncore \\
\hline OC85 (OC3.2E8) & NF150 & Peripheral, nonphosphorylated \\
\hline TA54 $(2.4 \mathrm{~F} 10)$ & NF150 & Core \\
\hline $\mathrm{TA} 34(2.2 \mathrm{~B} 12)$ & NF150 & Peripheral, phosphorylated \\
\hline TA50 (1.1C7) & NF200 & Peripheral, phosphorylated \\
\hline TA52 (2.2F3) & $\begin{array}{c}\text { NF150+ } \\
\text { NF200 }\end{array}$ & Peripheral, phosphorylated \\
\hline TA51 (4.3F9) & $\begin{array}{c}\text { NF150 + } \\
\text { NF200 }\end{array}$ & Peripheral, phosphorylated \\
\hline $2.2 \mathrm{~B} 10$ & GF protein & Undefined \\
\hline
\end{tabular}

The antibody code is in the left column, and its polypeptide specificity is indicated in the middle column. The right-hand column contains data on the topographical location and phosphorylation state of each epitope recognized by these monoclonal antibodies except for 2.2B10. The location of the NF150 and NF200 epitopes recognized by these antibodies in the peripheral (C-terminal or tail-piece) or core (alpha-helical) domains of these subunits is indicated ("peripheral" or "core," respectively). If phosphate residues are present in or near these epitopes such that their immunoreactivity is affected by enzymatic dephosphorylation, this fact is also noted. The NF68 epitope is unaffected by enzymatic dephosphorylation; it resides in the non-alpha-helical ("noncore") region of NF68. See Carden et al. (1985) for further details.

tracts of bovine spinal cord containing NF triplet proteins, glial (GF), and vimentin filament proteins, actin, tubulin, and other proteins; (3) immunofluorescence studies on acetone-fixed, frozen sections of bovine cerebellum; and (4) immunoperoxidase studies on paraffin sections of bovine cerebellum fixed by a number of different fixatives.

Recently, the NF epitopes recognized by these monoclonal antibodics were further defined with respect to their location in peripheral (Cterminal or tail-piece) versus core (alpha-helical) domains of NF150 and NF200, and core versus noncore regions of NF68 (see Carden et al., 1985, for details). Further, the effect of the phosphorylation state of NF150 and NF200 on the detection of these subunits with our antibodies has also been determined (Carden et al., 1985).

Of over 200 anti-NF protein monoclonal antibodies that we could select, seven met the following criteria for use in this study: (1) They are specific for only one or two NF subunits; (2) they detect NF antigens by immunoperoxidase methods; (3) they do not cross-react with fibroblast, muscle, or epithelial (i.e., vimentin, desmin, or keratin) antigens using these techniques; (4) they detect NF epitopes both in perikarya and processes of neurons. The latter point is critical since NF subunits contain epitopes that are preferentially expressed in different regions (cell body or processes) of a neuron (Goldstein et al., 1983). The monoclonal antibodies used in this study are listed in Table 1.

\section{Preparation of bovine tissue samples for immunohistochemistry}

Previous studies showed that bovine NF antigens are optimally detectable in paraffin sections following fixation of the tissues in Bouin's fixative or in a mixture of mercuric chloride and formaldehyde (Hickey et al., 1983). Accordingly, tissue fixed in Bouin's solution or a mixture of $4 \%$ mercuric chloride and $8 \%$ formaldehyde was used here. All tissue samples were trimmed fresh to 4-5 $\mathrm{mm}$ thick slabs and immersionfixed for 4-6 hr prior to paraffin embedding. The CNS and PNS tissues and other regions examined in this study are listed in Table 2.

\section{Immunohistochemical procedures}

The immunoperoxidase mcthods used here have been described (Trojanowski et al., 1984a). In brief, the monoclonal antibodies were applied to $6-\mu \mathrm{m}$-thick deparaffinized tissue sections as spent supernatants following quenching of endogenous peroxidase activity with methanol and hydrogen peroxide. Bound antibody was visualized with the peroxidase antiperoxidase (PAP) method (Sternberger, 1979) or the avidin-biotin method (Hsu et al., 1981). The linking antibody used in the PAP technique was purchased from Cappel Labs (Cochranville, PA), and the PAP reagent was obtained from Sternberger-Meyer (Jarretsville, MD). The avidin-biotin procedure was conducted according to the recommendations of the manufacturer (Vector Labs, Burlingame, CA).
Table 2. Immunohistochemical results

\begin{tabular}{|c|c|c|c|}
\hline Tissue & NF68 & NF150 & NF200 \\
\hline \multicolumn{4}{|l|}{ Neural tissues } \\
\hline *Carotid body & $P, N$ & $\mathrm{P}, \mathrm{N}$ & $P, N$ \\
\hline Cortex, cerbellar & $\mathbf{P}, \mathrm{N}$ & $\mathrm{P}, \mathrm{N}$ & $\mathrm{P}, \mathrm{N}$ \\
\hline Cortex, frontal & $P, N$ & $\mathrm{P}, \mathrm{N}$ & $\mathrm{P}, \mathrm{N}$ \\
\hline Cortex, occipital & $\mathrm{P}, \mathrm{N}$ & $P, N$ & $\mathrm{P}, \mathrm{N}$ \\
\hline Ganglia, enteric & $\mathrm{P}, \mathrm{N}$ & $\mathrm{P}, \mathrm{N}$ & $\mathrm{P}, \mathrm{N}$ \\
\hline Ganglia, sympathetic & $\mathrm{P}, \mathrm{N}$ & $\mathrm{P}, \mathrm{N}$ & $P, N$ \\
\hline Ganglia, trigeminal & $\mathrm{P}, \mathrm{N}$ & $\mathrm{P}, \mathrm{N}$ & $P, N$ \\
\hline Hypothalamus & $\mathrm{P}, \mathrm{N}$ & $\mathrm{P}, \mathrm{N}$ & $\mathrm{P}, \mathrm{N}$ \\
\hline Optic nerve & $\mathrm{N}$ & $\mathrm{N}$ & $\mathrm{N}$ \\
\hline *Pineal gland & $\mathrm{P}, \mathrm{N}$ & $P, N$ & $\mathrm{P}, \mathrm{N}$ \\
\hline Retina & $\mathrm{P}, \mathrm{N}$ & $\mathrm{P}, \mathrm{N}$ & $\mathrm{P}, \mathrm{N}$ \\
\hline Spinal cord & $\mathrm{P}, \mathrm{N}$ & $\mathrm{P}, \mathrm{N}$ & $\mathrm{P}, \mathrm{N}$ \\
\hline
\end{tabular}

Endocrine tissues

Adrenal gland

Cortex

*Medulla

*Pancreas

*Parathyroid gland

Pituitary gland

*Pars distalis

Pars intermedia

Pars nervosa

*Submandibular gland

*Thyroid gland

$\begin{array}{llll}\text { N } & \text { N } & \text { N } & \text { A } \\ \text { P, N } & \text { P, N, O } & \text { P, N } & \text { A } \\ \text { N } & \text { P, N } & \text { P, N } & \text { A } \\ \text { N } & \text { N } & \text { N } & \text { A }\end{array}$

Other tissues

Blood vessels
*Intestinal mucosa
Kidney
Lens
Liver
*Lung
Lymph node
Muscle
Skin
Spleen
Testis
Thymus

$\begin{array}{llll}\text { N, O } & \text { N, O } & \text { N, O } & \text { A } \\ \text { N, O } & \text { N, O } & \text { N, O } & \text { A } \\ \text { N } & \text { N } & \text { N } & \text { G } \\ \text { N } & \text { N } & \text { N } & \text { A } \\ \text { N } & \text { N } & \text { N } & \text { A }\end{array}$

The presence or absence of the three NF subunits and GF protein in each tissue is indicated as follows: $A=$ absence of immunoreactivity; $G=G F$-positive cells (astrocytes in the CNS, enteric glia in the PNS); N = NF-positive neurites (axons and dendrites); $\mathrm{P}=\mathrm{NF}$-positive neuronal perikarya; $\mathrm{O}=\mathrm{NF}$-positive cells other than classical neurons or glia (in adrenal medulla, $\mathrm{O}=$ chromaffin cells; in intestinal mucosa, $\mathrm{O}=$ enterochromaffin cells; in pars intermedia and pars distalis, $\mathrm{O}=$ cell bodies). An asterisk (*) identifies components of the diffuse neuroendocrine system (Marangos et al., 1982; Nolan et al., 1985).

To reveal potentially masked antigen determinants, selected monoclonal antibodies were applied to sections pretreated for $30 \mathrm{~min}$ with one of the following: $0.1 \%$ SDS, $0.5 \%$ Triton $X-100$, or $0.1 \%$ trypsin, as detailed elsewhere (Trojanowski et al., 1984a). Additional immunohistochemical studies were conducted on selected sections using goldlabeled antibodies. Briefly, colloidal gold- ( $40 \mathrm{~nm}$ gold granules) labeled rabbit anti-rat IgG (Janssen Pharmaceutica, Belgium) was applied undiluted or diluted (1:5 with $0.5 \mathrm{M}$ Tris buffer, $\mathrm{pH} 7.4$, with $2 \%$ fetal calf serum) for $\mathrm{l}$ hr to tissue sections previously incubated with hybridoma supernatant as in the immunoperoxidase studies.

Following the immunohistochemical procedures, all of the sections were washed, dehydrated, coverslipped, and examined with or without a counterstain. 


\section{Controls and data evaluation}

Spent supernatant from unfused mouse myeloma cells was used in parallel with the monoclonal antibodies to monitor nonspecific staining. In addition, a monoclonal antibody specific for bovine GF protein (Lee et al., 1984) was used in parallel with the other antibodies as a control. GF protein, initially isolated from gliotic brain (Eng et al., 1971), is the major protein of the intermediate filaments of astrocytes; it is also present in enteric glia and a few other cell types (see review by Eng and DeArmond, 1983).

Since axons were nearly ubiquitous in the tissues assayed, they provided endogenous positive controls for the anti-NF monoclonal antibedies. A section of bovine cerebellum was included in each experiment to provide a positive control for the monoclonal antibody to GF protein. Only experiments in which all of these controls were successfully executed underwent further evaluation for inclusion in this study.

The immunohistochemical results were evaluated as in a previous study (Hickey et al., 1983). The presence or absence of NF68, NF150, NF200, and GF immunoreactivity in consecutive sections from each tissue was tabulated.

\section{Results}

\section{General observations}

The sensitivity of the immunoperoxidase methods exceeded that of the immunogold method. The results in Bouin's and mercuric chloride/formaldehyde-fixed tissues were similar. NF and GF immunoreactivity in neurons and glia, respectively, was always diffuse; no aggregates of NF immunoreactivity, similar to those in transformed cells (Lee, 1985; Lee and Page, 1984; Lee et al., 1982a; Trojanowski et al., 1984b) were seen. The results obtained using the PAP and avidin-biotin methods were equivalent, and treatment of the scctions with Triton, trypsin, or SDS did not improve the results. Except for the fact that TA54 weakly stained neurons and axons, possibly because of the core location of the epitope it recognizes, no simple correlation between the expression of an NF epitope and its domain or phosphorylation status was evident. The immunoperoxidase results are considered in further detail below (see also Table 2 and Figs. 1-6).

\section{Immunoreactive $N F$ subunits in the $C N S$}

Consecutive sections of frontal, occipital, and cerebellar cortex were examined in addition to consecutive sections of hypothalamus, optic ncrve, pincal gland, retina, and spinal cord. In each region, neurites (axons and dendrites) consistently contained each of the NF subunits. In subcortical white matter (Fig. 1, $A-C$ ), optic nerve (Fig. 2A) and spinal cord, where it was possible to survey larger numbers of axons, all identifiable axons cxpressed NF68, NF150, and NF200 immunoreactivity. In areas enriched in neuron cell bodies, such as cortex, hypothalamus, spinal cord, or retina, large numbers of neuronal perikarya were immunostained with each of the NF subunit specific monoclonal antibodies. However, neurons with low levels of or no detectable immunoreactivity, regardless of the subunit specific monoclonal antibody used, were frequently seen (Fig. 1, $A-C$ ). These were generally smaller neurons with scant cytoplasm, such as those in granular layers of cerebral cortex or the granular cell neurons of cerebellar cortex. In the pineal gland (Fig. 2C), only rare cell bodies with NF immunoreactivity were seen (a maximum of 3-5 per horizontal section through the entire pineal). Immunostained axons were similarly infrequent in the pineal gland. The scarcity of neurons and axons in the pineal is consistent with current views on the histological composition of this gland (Weiss, 1983). No other elements in any of these CNS regions (i.e., blood vessels, glial cells, leptomeninges, etc.) contained NF immunoreactivity.

In adjacent control sections from these same tissues, the monoclonal antibody to GF protein intensely stained numerous fibrous astocytes; protoplasmic astrocytes were weakly and infrequently immunostained (Fig. 1D). In the optic nerve (Fig. $2 B$ ) and pineal gland (Fig. 2D), GF protein-positive astrocytes were numerous. No GF immunoreactivity was seen in neurons, ependymal or oligodendroglial cells, myelin, blood vessels, etc.

\section{Immunoreactive NF subunits in the PNS}

Consecutive sections of the carotid artery bifurcation and carotid body, paravertebral sympathetic ganglia, and trigeminal ganglia were immunostained with the anti-NF monoclonal antibodies. In addition, enteric ganglia of the small and large intestines and a number of other microscopic ganglia lying within or adjacent to other tissues, such as the submandibular gland, pancreas, etc., were similarly immunostained. In each of these tissues, NF-positive neurites were prominent. All identified clusters of axons were immunostained by each NF subunit specific antibody. No axon clusters failed to express all of the NF triplet proteins. This was most evident within and around ganglia (Figs. $3, A-C ; 4, A-C ; 5, A, D$ ), where densely packed immunostained axons could be compared in adjacent sections.

Neuronal perikarya in these ganglia exhibited intense immunoreactivity for each of the NF subunits (Figs. 3, $A-C ; 4, A-$ $C ; 5, A$ and $D$ ). In contrast with the findings in the CNS, nearly every PNS neuron exhibited immunoreactivity for each of the NF subunits; negative neurons were exceptional (compare Fig. 1, $A-C$ with Fig. 3, $A-C$ ). Although formal quantitation was not undertaken, fewer than $1 \%$ of identified PNS neurons lacked NF protein immunoreactivity, while as many as $30 \%$ of neurons in a given CNS region lacked NF immunoreactivity. However, the PNS neurons were uniformly large, with abundant cytoplasm (Figs. 3-5), whereas populations of smaller neurons were frequent in the CNS.

One of the anti-NF1 50 monoclonal antibodies (OC85) yielded a pattern of immunoreactivity in the intestine that differed from all of the others. It stained neuronal perikarya and neurites, as did the other anti-NF monoclonal antibodies, but in addition it stained scattered enterochromaffin cells (Marangos et al., 1982; Nolan et al., 1985; Weiss, 1983) of the intestine (Fig. 5C). The failure of any of the other monoclonal antibodics to immunostain these cells and the failure of this antibody to stain other cells in endocrine tissues (e.g., submandibular, pancreas, parathyroid, or thyroid glands) suggests that OC 85 cross-reacts with an antigen specific to enterochromaffin cells. Dilution of OC85 1:50 with Tris buffer eliminated all neuronal staining, but it still stained enterochromaffin cells intensely (Fig. $5 \mathrm{C}$ ).

NF immunoreactivity in the carotid body differed from that observed in PNS ganglia; only a few ganglion cells were stained with the NF subunit-specific monoclonals (Fig. 6C). Some of these NF-positive neurons were also seen outside the carotid body in the wall of the adjacent carotid artery (Fig. 6D). Axons in the vicinity of the carotid body were uniformly positive with each of the anti-NF monoclonal antibodies (Fig. 6C). On the other hand, none of the smaller cells within the carotid body was similarly immunostained. Muscle cells and fibroblasts in the carotid artery were also negative. No blood vessels other than the carotid artery contained similar NF-positive neurons within their walls.

Other than the neurons and neuronal processes described above, no other elements in the tissues described here were immunostained with these anti-NF monoclonal antibodies.

In consecutive control sections through the same PNS tissues, only glial cells in enteric ganglia of the intestine expressed GF protein (Fig. 5B). Rarely, an occasional satellite cell was immunostained with the monoclonal antibody to GF protein (Fig. $4 D$ ). Consistent with earlier immunoperoxidase studies of normal and degenerating rat and human peripheral nerve, we did not detect GF immunoreactivity in Schwann cells (Trojanowski et al., 1984b). Whether Schwann cells express the same GF 

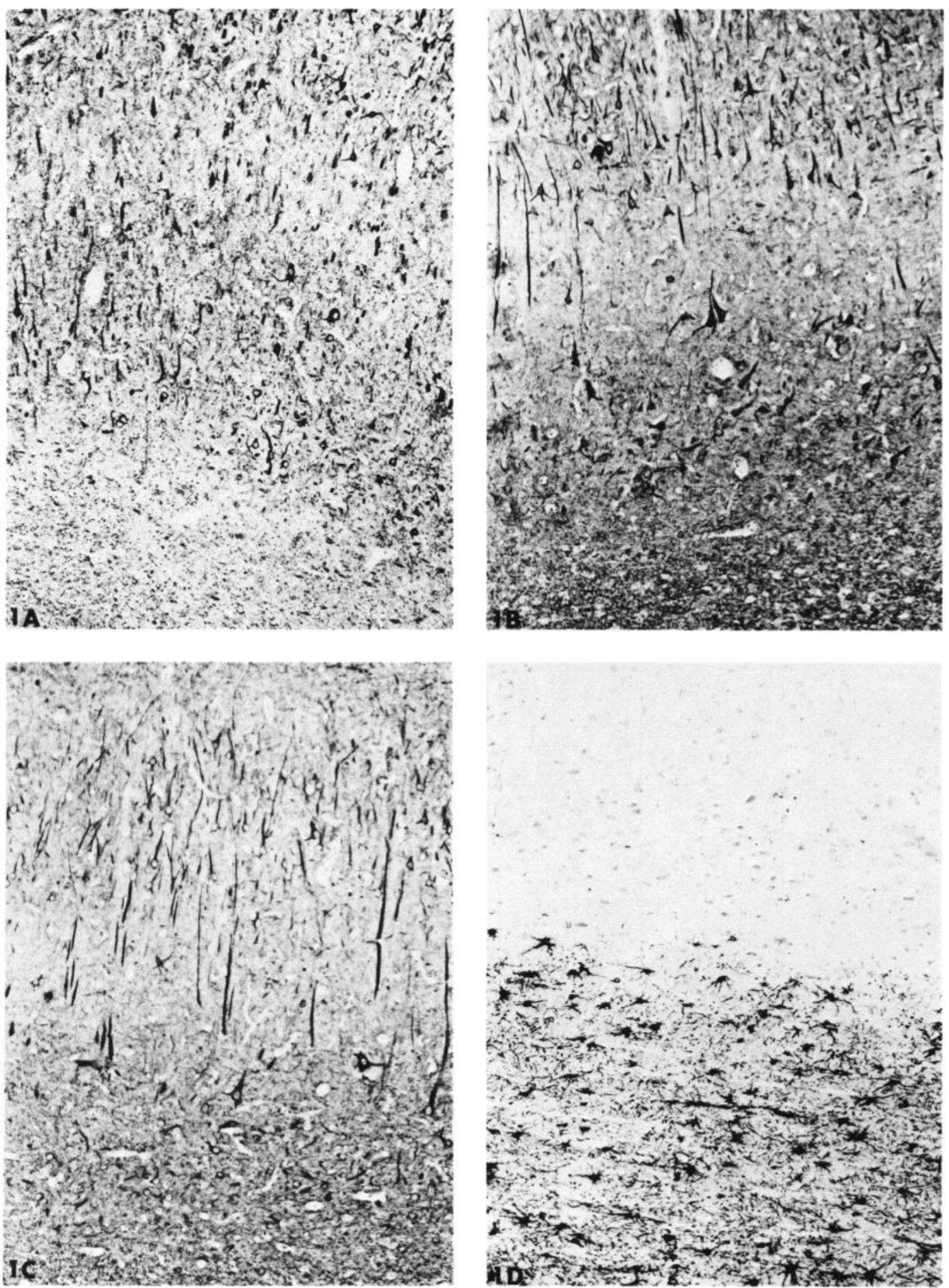

Figure 1. Consecutive sections through layers III-VI and the subcortical white matter of occipital cortex immunostained with monoclonal antibodies to NF68 (SE3 in $A$ ), NF150 (OC85 in $B$ ), NF200 (TA50 in $C$ ), and GF protein (2.2B10 in $D$ ). Most neuronal perikarya express each of the NF subunits; NF-negative neurons are predominantly small and located in the granular layer of cortex. GF immunoreactivity is restricted almost exclusively to fibrous astrocytes; protoplasmic astrocytes are infrequently immunostained. All of the sections in Figures 1-6 were counterstained with hematoxylin and enlarged $\times 250$, except Figure $5 B$, which is enlarged $\times 500$.

protein present in astrocytes remains unresolved (Dahl et al., 1982; Eng and DeArmond, 1982; Schlaepfer et al., 1979).

\section{Immunoreactive NF subunits in endocrine and} other tissues

Consecutive sections through endocrine tissues, including the adrenal gland, pancreas, parathyroid gland, pituitary gland, submandibular gland, and thyroid gland, were examined with the monoclonal antibodies to NF subunits. A variety of other tissues were also examined in the same manner, including large blood vessels (both arteries and veins), kidney, lens, liver, lung, lymph nodes, skin, smooth and striated muscle, spleen, testis, and thymus.

The pattern of NF immunoreactivity in the adrenal and pituitary glands differed from that seen in the other tissues discussed in this section. A dense plexus of neurites in the adrenal 

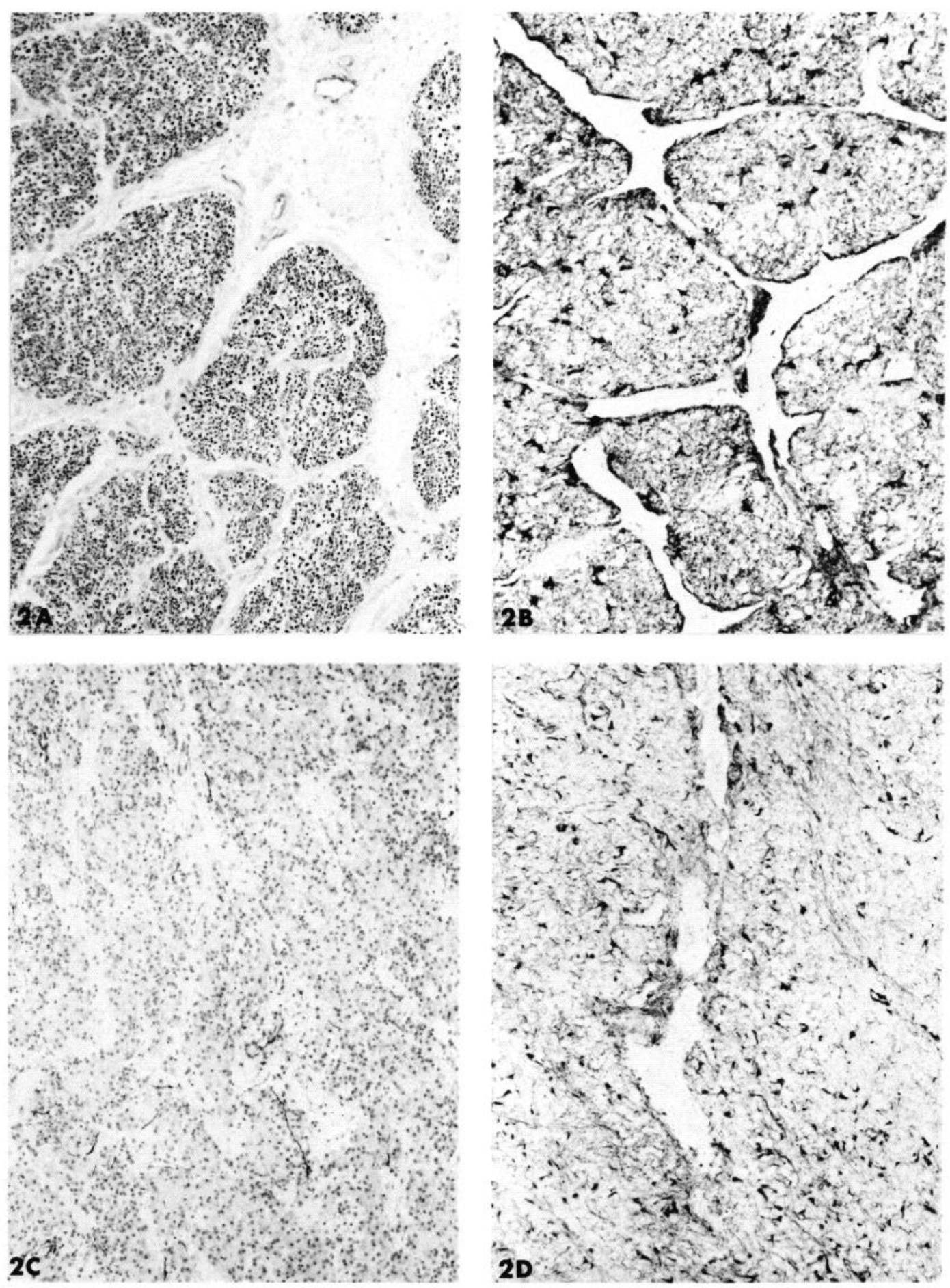

Figure 2. Consecutive transverse sections through optic nerve $(A, B)$ and pineal gland $(C, D)$ immunostained with a monoclonal antibody specific for NF68 (SE3 in $A$ ) or NF150 and NF200 (TA51 in $C$ ) or for GF protein (2.2B10 in $B$ and $D$ ). All optic nerve axons contain NF immunoreactivity; astrocytes are GF-positive. In the pineal gland, NF-positive neurons and neurites are rare; numerous astrocytes with immunoreactive GF are seen.

medulla (Fig. $6 \mathrm{~A}$ ) was immunostained with each of the anti-NF antibodies, as were occasional ganglion cells (one to five per section of adrenal medulla). Chromaffin cells were negative in sections stained with the antibodies specific for NF68 or NF200, but those specific for NF150 or for NF150 and NF200 stained numerous adrenal chromaffin cells. Adrenal cortical cells were negative, but NF-positive axons in large nerves of the cortex were observed.

In the pituitary gland, the pars nervosa contained numerous axons that were positively stained with monoclonal antibodies specific for each of the NF subunits; a few of these axons extended into the pars intermedia and pars nervosa (Fig. $6 B$ ). Aggregates of NF protein immunoreactivity, which appeared to be in the extracellular space of the pars nervosa, were also noted. In addition, rare cell bodies scattered in the pars intermedia and pars distalis near the pars nervosa were immunostained with the monoclonal antibodies specific for NF68, NF150, and NF200; none were present in the pars nervosa (Fig. 6B). 

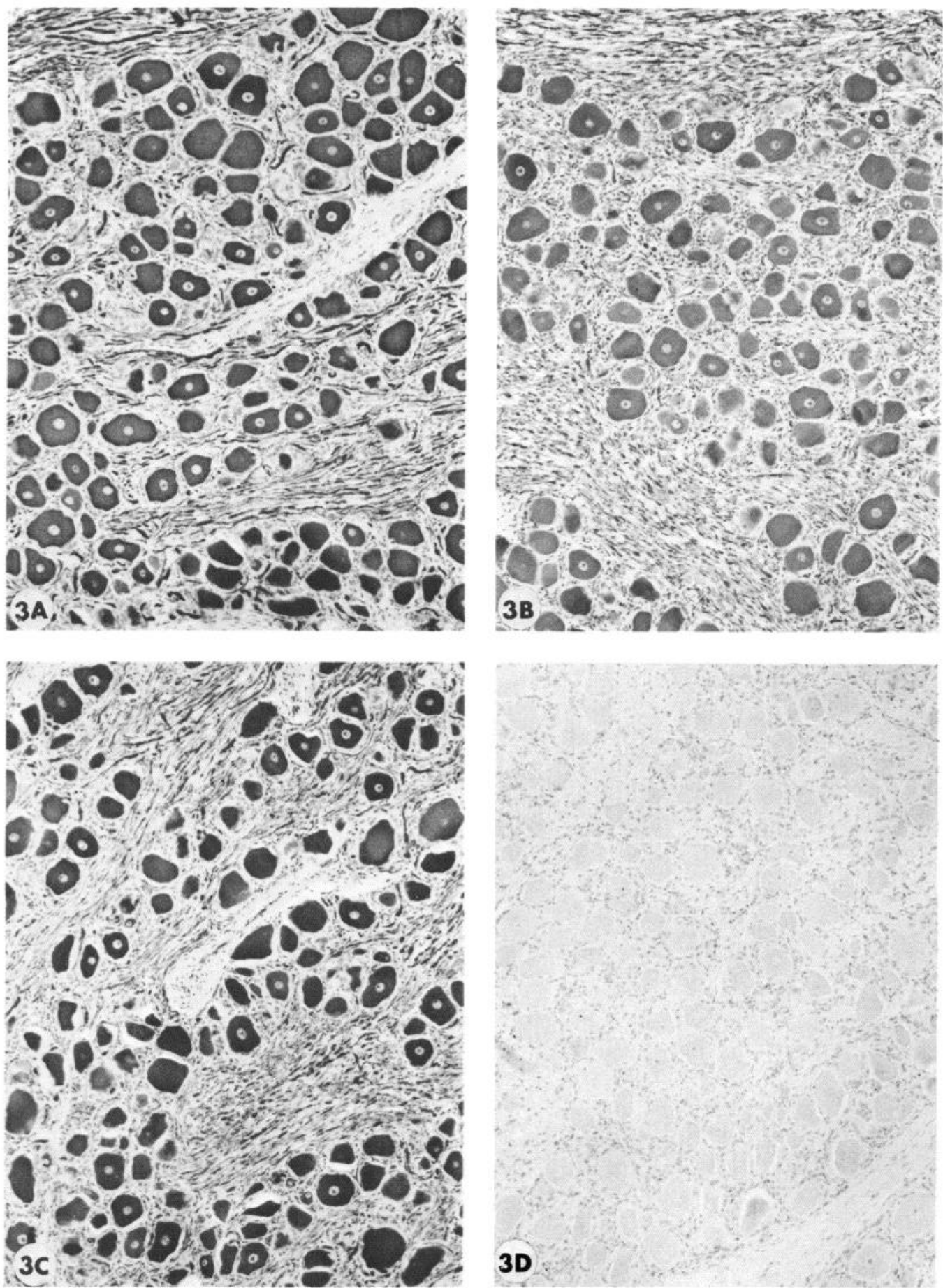

Figure 3. Consecutive sections through trigeminal ganglion immunostained with monoclonal antibodies to NF68 (SE3 in $A$ ), NF150 (TA34 in $B$ ), NF200 (TA50 in C), or GF (2.2B10 in D). All neurons are positive for each NF subunit; no GF-positive glial cells are seen.

The parenchyma of the other organs discussed in this section was devoid of any NF immunoreactivity except for that seen in nerves traversing each organ. The walls of arteries and veins were devoid of immunostained axons or cell bodies except in the vicinity of the carotid artery, as described above. Axons with immunoreactive NF68, NF150, and NF200 were seen in sections from each of these organs, but they were not as numerous as those seen in the adrenal or pituitary glands (see below). Immunostained nerves were relatively rare ( $0-10$ nerve fascicles per section) in these tissues; they were most prominent in the capsule of these organs and less frequent in the paren- chyma (see Fig. 5, $A$ and $D$ ). Occasional ganglia comprised of 10-20 neurons containing immunoreactive NF68, NF150, and NF200 were seen at the periphery of some of the endocrine tissues (Fig. 5D).

Aside from the cells and processes described above, no other NF immunoreactivity was seen in any of the other components of the tissues listed in Table 2 .

In consecutive control sections of the same tissues considered here, only occasional astrocytes in the pars nervosa were GF positive. Although Hatfield et al. (1984) have recently demonstrated GF protein in the epithelium of mouse lens using 

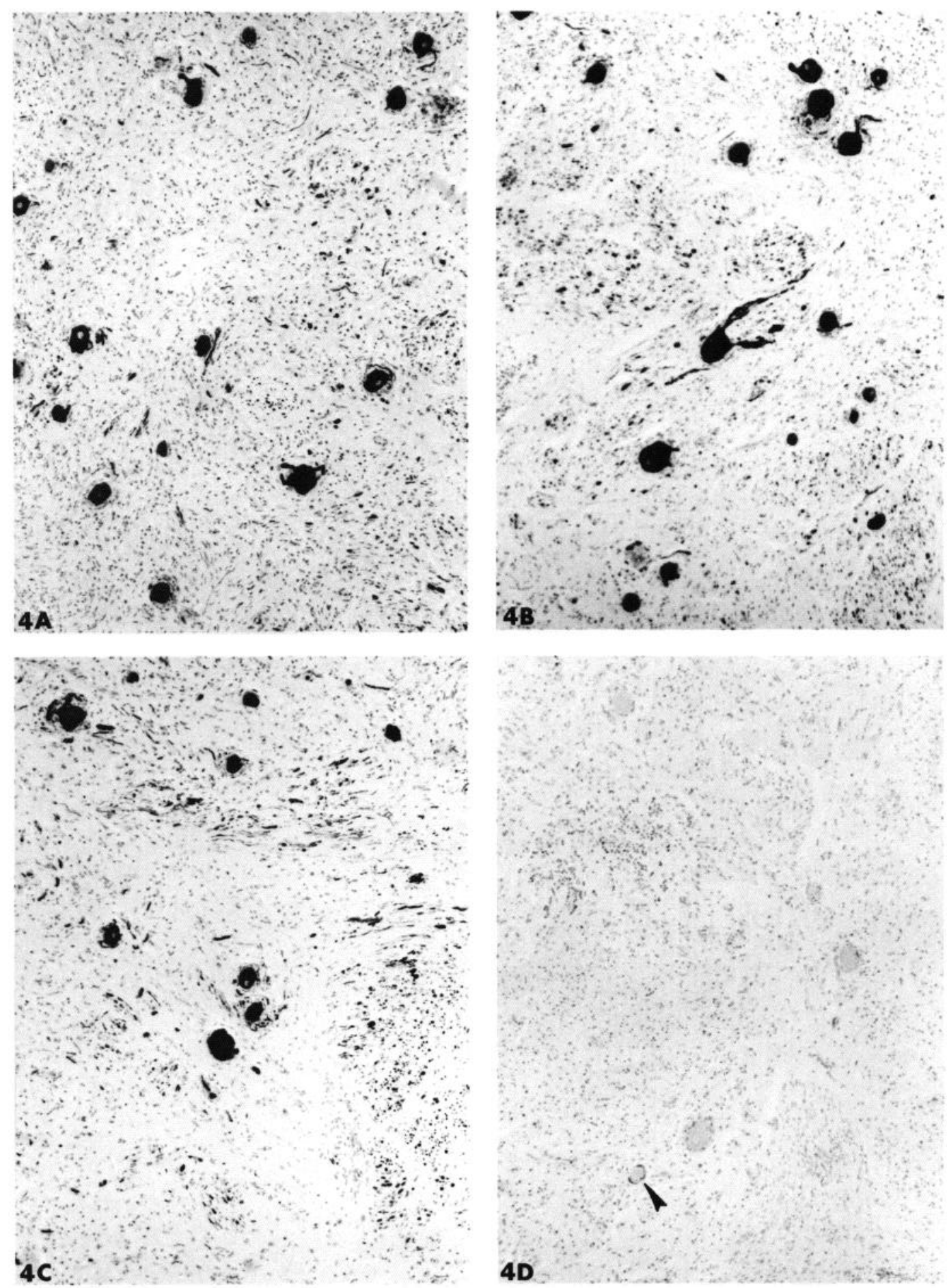

Figure 4. Consecutive sections through an autonomic ganglion immunostained with monoclonal antibodies to NF68 (SE3 in $A$ ), NF150 (TA34 in $B$ ), NF200 (TA50 in C), and GF protein (2.2B10 in D). All neurons are positive for each NF subunit. No glial cells contain GF protein with the exception of a rare satellite cell (arrowhead).

antiserum raised to human GF antigens, bovine lens was negative when stained with our monoclonal antibody to bovine GF protein.

Although the monoclonal antibody to bovine GF protein was used as a control antibody in these studies, it is of interest to note that, with the few exceptions pointed out earlier, the GF protein epitope recognized by this monoclonal antibody has a distribution similar to that observed in other immunohistochemical studies using anti-GF protein antiserum (Eng and DeArmond, 1982).

\section{Discussion}

These studies demonstrate the ubiquitous distribution of each of the three NF subunits in diverse populations of PNS neuronal perikarya and in diverse populations of PNS and CNS axons using well-characterized monoclonal antibodies and immunohistochemistry. The majority of CNS neuronal perikarya also contained each of these antigens. This has important implications for hypotheses concerning the structure and function of the intermediate filaments of neurons. 

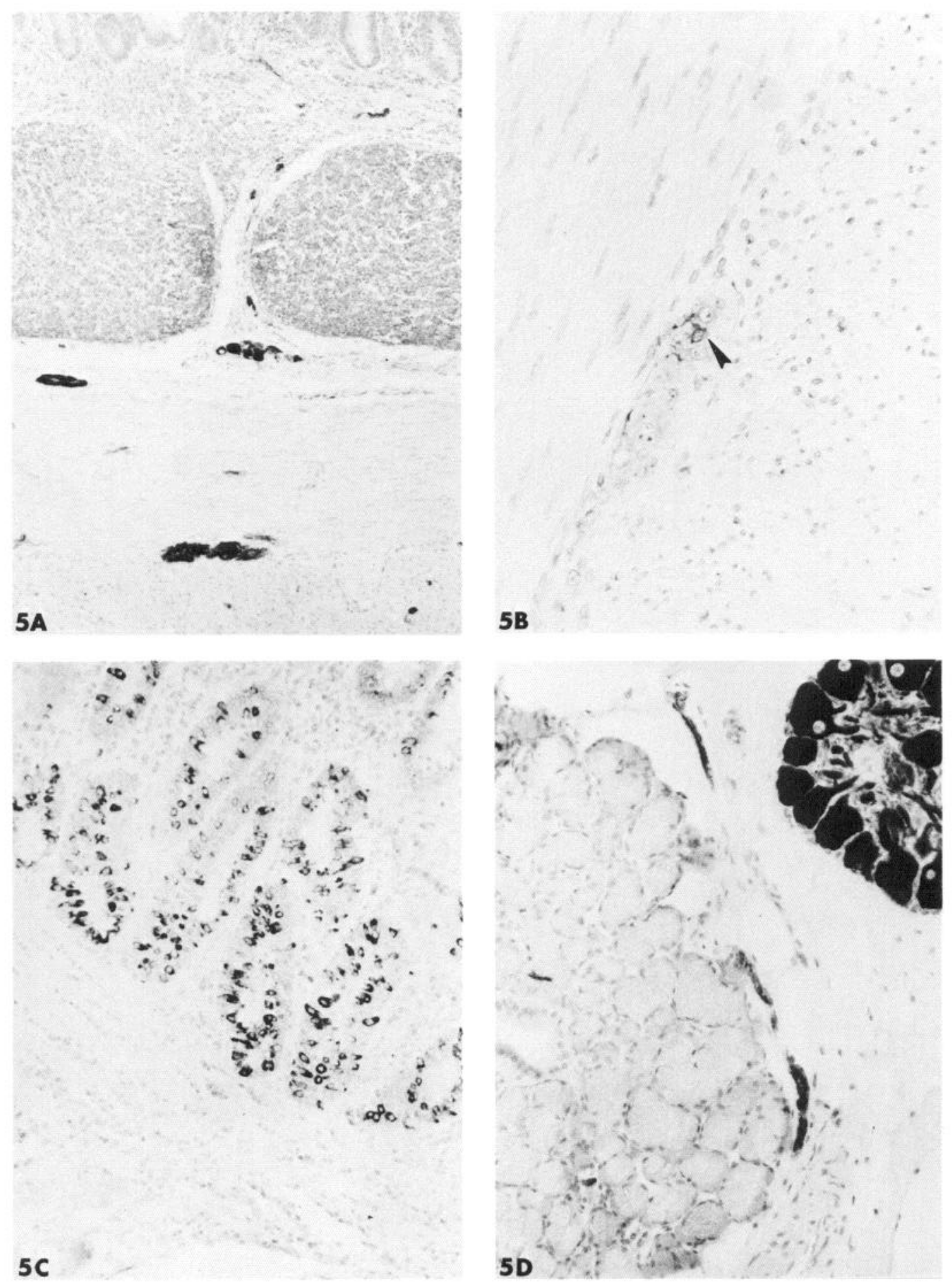

Figure 5. Sections through intestine $(A-C)$ and submandibular gland $(D)$ immunostained with monoclonal antibodies to NF200 (TA50 in $A$ and $D$ ), a monoclonal antibody (OC85) specific for NF150 (C), and the anti-GF monoclonal antibody (2.2B10 in $B)$. All of the neurons and axons in $A$ and $D$ are NF-positive. Enteric glia $(B$, arrowhead) express GF protein. OC 85 cross-reacts with enterochromaffin cell-specific antigens $(D)$. Diluted 1:50 here, OC 85 does not immunostain neurons and axons, while enterochromaffin cells are still positive. OC 85 was the only anti-NF monoclonal antibody in this study that stained enterochromaffin cells.

Our data support the generality of current models of NF structure, which indicate that the intermediate filaments of neurons are comprised of a triplet (NF68, NF150, NF200) of polypeptides (Liem et al., 1978; Schlaepfer and Freeman, 1978). The immunohistochemical demonstration of NF68, NF150, and NF200 antigens in neurons means that these subunits are available for incorporation into NFs, but it does not prove they are assembled into filaments. However, it is known that mamma- lian NF proteins are insoluble on extraction in Triton X-100 (Liem et al., 1978; Schlaepfer and Freeman, 1978), and that these Triton-insoluble extracts contain 10-nm-diameter filaments that can be decorated by antibodies specific for each of these subunits (Schlaepfer et al., 1981; Sharp et al., 1982, Willard and Simon, 1981). This suggests that the monoclonal antibodies used in these studies probably bind to NF subunits assembled into filaments. Our data are also important for evaluating hy- 

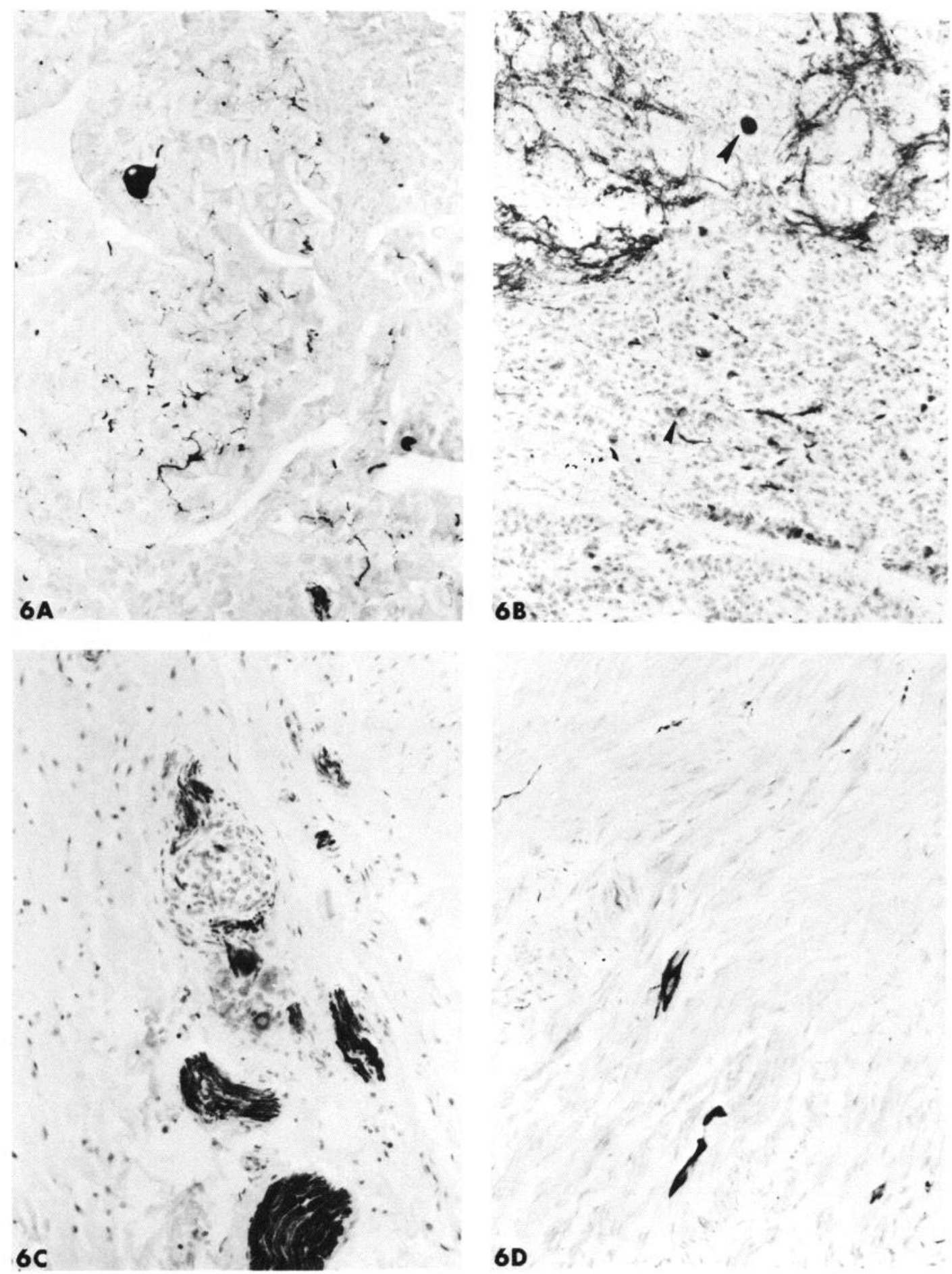

Figure 6. Sections of adrenal medulla $(A)$, pituitary gland $(B)$, carotid body $(C)$, and adjacent carotid artery $(D)$ immunostained with a monoclonal antibody specific for both NF150 and NF200 (TA51). In the adrenal medulla many labeled neurites and a labeled ganglion cell are seen. Chromaffin cells contain NF immunoreactivity not apparent at this magnification. In the pars nervosa ( $B$, upper half) axons are NF-positive; some NF immunoreactivity is in aggregates that may be extra-axonal (large arrowhead). A few cells in the pars intermedia also contain NF immunoreactivity (small arrowheads). In the carotid body, neurons and axons contain NF immunoreactivity. NF-positive neurons are seen also in the adjacent wall of the carotid artery $(D)$. No other blood vessels contained similar NF-positive cells. $\times 250$.

potheses concerning the function of mammalian NFs. The nearubiquitous presence of each of the NF polypeptides in mature CNS and PNS neurons and their processes, coupled with their absence in other mature cell types, suggests that NFs subserve some unique neuronal function.

The data presented here must be viewed with the limitations of immunohistochemistry in mind. Although the specificities of the monoclonal antibodies used in this study for bovine NF proteins have been rigorously evaluated (Carden et al., 1985; Hickey et al., 1983; Lee et al., 1982b, 1984), immunohistochemistry alone cannot provide conclusive proof that the antigens detected in situ with these antibodies are indeed NF polypeptides. It is known that antibodies may recognize epitopes in unrelated proteins (Dulbecco et al., 1981), in addition to the 
immunogens against which they are raised. Monoclonal antibodies that detect epitopes shared by more than one class of intermediate filaments have been described (Lee and Page, 1984; Lee et al., 1984; Pruss et al., 1981) and antiserum to a synthetic peptide has been shown to cross-react with NF150 in mice and guinea pigs (Drager et al., 1983; Trojanowski et al., 1985). Further, possibly because NF subunits may undergo posttranslational modifications, or because of other yet-to-be-defined factors that affect the immunoreactivity of NF subunits, anti-NF monoclonal antibodies may detect NF proteins in axons but fail to recognize them in neuronal perikarya, where they are synthesized (Gown and Vogel, 1984; Hickey et al., 1983; Sternberger and Sternberger, 1983).

Conclusive proof that the antigens stained here are indeed NF subunits would require their isolation from the immunostained cells. NF proteins have been isolated from some of the tissues studied here, e.g., from peripheral nerve and spinal cord (Carden et al., 1985; Liem et al., 1978; Schlaepfer et al., 1979), and retina, optic nerve, and pars nervosa (Trojanowski et al., 1985). However, since nerves are ubiquitous, attempts to extract NF proteins from distinct populations of cells in the tissues examined here would result in the contamination of such extracts by the NF proteins in peripheral nerves. The isolation of NF proteins from cells grown in primary culture is possible. For example, NF proteins have been isolated from cultured adrenal chromaffin cells (Bader et al., 1984) and sympathetic neurons (Lee, 1985). However, this strategy also has limitations. For example, different tissue culture conditions dramatically affect the expression of NF and GF proteins in cultured cells (Lee, 1985; Lee and Page, 1984; Raff et al., 1983). This may explain why we detected only NF150 in bovine adrenal chromaffin cells in situ, whereas Bader et al. (1984) detected all three NF proteins in primary cultures of bovine adrenal chromaffin cells.

In order to overcome the limitations inherent in immunohistochemistry, we utilized a panel of monoclonal antibodies with exhaustively characterized specificities for different bovine intermediate filament proteins and applied them to a wide range of tissues fixed by different methods. We also employed the most sensitive currently available immunoperoxidase methods (Hsu et al., 1981; Sternberger, 1979). Finally, we used monoclonal antibodies raised against immunogens from the same species in which the immunohistochemical studies were conducted. This is of critical importance in view of the marked immunochemical differences in NF proteins of even closcly related species (Shaw and Weber, 1984; Shaw et al., 1984). For example, in our library of anti-NF150 monoclonal antibodies, only those that see core (in contrast to peripheral) NF150 epitopes recognize rat NF150 (Lee et al., unpublished observations). Thesc factors alone could account for the failure to detect NF subunits in some neurons if the antibodies used to localize these antigens in a given species were raised and characterized using NF proteins from another species.

Despite the exhaustive characterization of these monoclonal antibodies, a novel cross-reaction was observed in gut; one of the anti-NF150 monoclonal antibodies (OC85) cross-reacted with an antigen restricted to enterochromaffin cells. This antigen is unlikely to be neuron-specific enolase or chromogranin, both of which are widely distributed throughout the diffuse neuroendocrine system (Marangos et al., 1982; Nolan et al., 1985). Additional studies will be necessary to define the nature of this cross-reaction. Since antiserum raised to synthetic alpha-MSH cross-reacts with an epitope present in NF150 (Drager et al., 1983; Trojanowski et al., 1985), it is not surprising that an antiNF monoclonal antibody cross-reacts with antigens unrelated to NF proteins.

The failure to detect bovine NF antigens in some of the bovine neurons studied here is intriguing, but it must be interpreted with caution. Because the NF-negative neurons were predom- inantly small, with scant cytoplasm, the absence of NF immunoreactivity may be a false-negative result due to low levels of NF antigens. Since all identified axons expressed NF antigens, it is possible that NF subunits are rapidly exported to neuronal processes following synthesis and that only small amounts of NF antigens remain in the perikaryon of some neurons. Alternatively, the functional state of the cell, at the time of fixation (mediated by yet to be defined processes), could modify the epitopes detected by our monoclonal antibodies in selected neurons. Finally, it is possible that some neurons indeed lack NF subunits. However, we speculate that this is a less likely possibility than the others mentioned above.

With these cautions in mind, we feel that our data suggest that the expression of all three NF subunits is a fundamental property of CNS and PNS neurons and their processes. These observations are important for the formulation of hypotheses concerning the structure and function of NF proteins. They also have implications for hypotheses concerning the etiology of neurodegenerative diseases that putatively affect the intermediate filaments of neurons (Autilio-Gambetti et al., 1983; Schlaepfer, 1983).

Note added in proof. Our findings here with the monoclonal antibody $2.2 \mathrm{~B} 10$ raised to astrocyte GF protein are similar to those reported by Jessen et al. [(1984) J. Neurocytol. 13: 187200] for another monoclonal antibody (anti-GFAP-3) raised to astrocyte GF protein. The epitope recognized by these two antibodies is expressed by GF protein of astrocytes and enteric glia.

\section{References}

Autilio-Gambetti, I., P. Gambetti, and R. Crane (1983) Paired helical filaments: Relatedness to neurofilaments shown by silver staining and reactivity with monoclonal antibodies. In Biological Aspects of Alzheimer's Disease, R. Katzman, ed., pp. 117-124, Banbury Report Series, Cold Spring Harbor Laboratory, NY.

Bader, M. F., E. Georges, W. E. Mushynski, and J. M. Trifaro (1984) Neurofilament proteins in cultured chromaffin cells. J. Neurochem. 43: 1180-1193.

Carden, M. J., W. W. Schlaepfer, and V. M.-Y. Lee (1985) The structure, biochemical properties and immunogenicity of neurofilament peripheral regions are determined by phosphorylation. J. Biol. Chem. 260: 9805-9817.

Czosnek, H., D. Soifer, and H. M. Wisniewski (1980) Studies on the biosynthesis of neurofilament proteins. J. Cell Biol. 85: 726-734.

Dahl, D. (1983) Immunohistochemical differences between neurofilaments in perikarya, dendrites and axons. Exp. Cell Res. 149: 397408.

Dahl, D., N. H. Chi, L. E. Miles, B. T. Nguyen, and A. Bignami (1982) Glial fibrillary acidic (GFA) protein in Schwann cells: Fact or artifact. J. Histochem. Cytochem. 30: 912-918.

Drager, U. C., D. L. Edwards, and J. Kleinschmidt (1983) Neurofilaments contain a-melanocyte-stimulating hormone (a-MSH)-like immunoreactivity. Proc. Natl. Acad. Sci. USA 80: 6408-6412.

Dulbecco, R., M. Unger, M. Bologna, H. Battifora, P. Syka, and S. Okada (1981) Cross-reactivity between Thy-1 and a component of intermediate filaments demonstrated using a monoclonal antibody. Nature 292: 772-774.

Eng, L. F., J. J. Vanderhagen, A. Bignami, and B. Gerstl (1971) An acidic protein isolated from fibrous astrocytes. Brain Res. 28: 351354.

Eng, L. F., and S. J. DeArmond (1983) Immunochemistry of the glial fibrillary acidic protein. In Progress in Neuropathology, H. M. Zimmerman, ed., pp. 19-39, Raven, New York.

Goldstein, M. E., L. A. Sternberger, and N. H. Sternberger (1983) Microheterogeneity ("neurotypy") of neurofilament proteins. Proc. Natl. Acad. Sci. USA 80: 3101-3105.

Gown, A. M., and A. M. Vogel (1984) Monoclonal antibodies to human intermediate filament proteins. II. Distribution of filament proteins in normal human tissues. Am. J. Pathol. 114: 309-321.

Hatfield, J. S., R. P. Skoff, H. Maisel, and L. F. Eng (1984) Glial fibrillary acidic protein is localized in the lens epithelium. J. Cell Biol. 98: 1895-1898. 
Hickey, W. F., V. Lee, J. Q. Trojanowski, L. J. McMillan, T. J. McKearn, J. Gonatas, and N. K. Gonatas (1983) Immunohistochemical applications of monoclonal antibodies against myelin basic protein and neurofilament triplet proteins: Advantages over antisera and technical limitations. J. Histochem. Cytochem. 31: 1126-1135.

Hirokawa, N., M. A. Glicksman, and M. B. Willard (1984) Organization of mammalian neurofilament polypeptides within the neuronal cytoskeleton. J. Cell Biol. 98: 1523-1536.

Hsu, S.-M., L. Raine, and H. Fanger (1981) Use of avidin-biotin peroxidase complex (ABC) in immunoperoxidase techniques. A comparison between $\mathrm{ABC}$ and unlabeled (PAP) procedures. J. Histochem. Cytochem. 29: 577-580.

Lee, V. M.-Y. (1985) Neurofilament abnormalities in PC12 cells: Comparison with neurofilament proteins of normal cultured rat sympathetic neurons. J. Neurosci. 5: 3039-3046.

Lee, V. M.-Y., and C. Page (1984) The dynamics of nerve growth factor-induced neurofilament and vimentin filament expression and organization in PC12 cells. J. Neurosci. 4: 1705-1714.

Lee, V. M.-Y., J. Q. Trojanowski, and W. W. Schlaepfer (1982a) Induction of neurofilament triplet proteins in $\mathrm{PC} 12$ cells by nerve growth factor. Brain Res. 238: 169-180.

Lee, V. M.-Y., H. L. Wu, and W. W. Schlaepfer (1982b) Monoclonal antibodies recognize individual neurofilament triplet proteins. Proc. Natl. Acad. Sci. USA 79: 6089-6092.

Lee, V. M.-Y., C. D. Page, H.-L. Wu, and W. W. Schlaepfer (1984) Monoclonal antibodies to gel excised glial filament protein and their reactivity with other intermediate filament proteins. J. Neurochem. 42: 25-32.

Liem, R. K. H., S.-H. Yen, G. B. Salomon, and M. L. Shelanski (1978) Intermediate filaments in nervous tissue. J. Cell Biol. 79: 637-645.

Marangos, P. J., J. M. Polak, and A. G. E. Pearse (1982) Neuronspecific enolase. A probe for neurons and neuroendocrine cells. Trends Neurosci. 5: 193-196.

Nixon, R. A., B. A. Brown, and C. A. Marotta (1982) Posttranslational modification of neurofilament protein during axoplasmic transport: Implications for regional specialization of CNS axons. J. Cell Biol. 94: $150-158$.

Nolan, J. A., J. Q. Trojanowski, and R. Hogue-Angeletti (1985) Neurons and neuroendocrine cells contain chromogranin: Detection of the molecule in normal bovine tissues by immunochemical and immunohistochemical methods. J. Histochem. Cytochem. 33: 791-798.

Ostermann, E., N. H. Sternberger, and L. A. Sternberger (1983) Immunocytochemistry of brain-reactive monoclonal antibodies in peripheral tissues. Cell Tissue Res. 228: 459-473.

Pruss, R. M., R. Mirsky, M. C. Raff, R. Thorpc, A. J. Dowding, and B. H. Anderton (1981) All classes of intermediate filaments share a common antigenic determinant defined by a monoclonal antibody. Cell 27: 419-428.

Raff, M. C., R. H. Miller, and M. Noble (1983) A glial progenitor cell that develops in vitro into an astrocyte or an oligodendrocyte depending on culture medium. Nature 303: 390-396.
Schlaepfer, W. W. (1983) Neurofilaments and the abnormal filaments of Alzheimer's disease. In Biological Aspects of Alzheimer's Disease, R. Katzman, ed., pp. 117-124, Banbury Report Series, Cold Spring Harbor Laboratory, NY.

Schlaepfer, W. W., and L. A. Freeman (1978) Neurofilament proteins of rat peripheral nerve and spinal cord. J. Cell Biol. 78: 653-662.

Schlaepfer, W. W., L. A. Freeman, and L. F. Eng (1979) Studies of human and bovine spinal nerve roots and the outgrowth of CNS tissues into the nerve root entry zone. Brain Res. 177: 219-229.

Schlaepfer, W. W., V. M.-Y. Lee, and H.-L Wu (1981) Assessment of immunological properties of neurofilament triplet proteins. Brain Res. 226: 259-272.

Sharp, G. A., G. Shaw, and K. Weber (1982) Immunoelectron-microscopical localization of the three neurofilament triplet proteins along neurofilaments of cultured dorsal root ganglion cells. Exp. Cell Res. 137: 403-413.

Shaw, G., and K. Weber (1984) The intermediate filament complement of the retina: A comparison between different mammalian species. Eur. J. Cell Biol. 33: 95-104.

Shaw, G., E. Debus, and K. Weber (1984) The immunological relatedness of neurofilament proteins of higher vertebrates. Eur. J. Cell Biol. 34: 130-136.

Shaw, G., M. Osborn, and K. Weber (1981) An immunofluorescence microscopical study of the neurofilament triplet proteins, vimentin and glial fibrillary acidic protein within the adult rat brain. Eur. J. Cell Biol. 26: 68-82.

Sternberger, L. A. (1979) Immunocytochemistry. Wiley, New York.

Sternberger, L. A., and N. H. Sternberger (1983) Monoclonal antibodies distinguish phosphorylated and nonphosphorylated forms of neurofilaments in situ. Proc. Natl. Acad. Sci. USA 80: 6126-6130.

Trojanowski, J. Q., V. M.-Y. Lee, and W. W. Schlaepfer (1984a) Neurofilament breakdown products in degenerating rat and human peripheral nerves. Ann. Neurol. 16: 349-355.

Trojanowski, J. Q., V. M.-Y. Lee, and W. W. Schlaepfer (1984b) An immunohistochemical study of human central and peripheral nervous system tumors using monoclonal antibodies against neurofilaments and glial filaments. Human Pathol. 15: 248-257.

Trojanowski, J. Q., R. A. Stone, and V. M.-Y. Lee (1985) Presence of an alpha-MSH-like epitope in the 150,000 Dalton neurofilament subunit from diverse regions of the CNS: An immunohistochenical and immunoblot study in guinea pig. J. Histochem. Cytochem. 33: 900-904.

Yen, S.-H., and K. L. Fields (1981) Antibodies to neurofilament, glial filament and fibroblastic intermediate filament proteins bind to different cell types in the nervous system. J. Cell Biol. 88: 115-126.

Weiss, L. (1983) Histology: Cell and Tissue Biology, 5th Ed., Elsevier, New York.

Willard, M., and C. Simon (1981) Antibody decoration of neurofilaments. J. Cell Biol. 89: 198-205. 